\title{
Price transmission in the international skim milk powder markets
}

\author{
Panos Fousekis ${ }^{\mathrm{a}}$ and Emmanouil Trachanas ${ }^{\mathrm{b}, *}$ \\ ${ }^{a}$ School of Economics and Finance, Massey University, Palmerston North 4442, New Zealand. \\ Email: p.fousekis@massey.ac.nz \\ bepartment of Accounting, Finance and Economics, Oxford Brookes University, Oxford OX33 \\ 1HX, UK.*Corresponding author. Email: etrachanas@brookes.ac.uk
}

This is an author-generated version

Applied Economics

http://dx.doi.org/10.1080/00036846.2016.1173183

\begin{abstract}
This article investigates the strength and the pattern of spatial price linkages in skimmed milk powder markets using monthly wholesale price data from three major producers and exporters (the USA, the EU, and Oceania) and the Nonlinear Autoregressive Distributed Lag Model. The results suggest that prices in the three regions considered are linked with stable long-run relationships. The Law of One Price, however, does not hold. The dominant pattern of transmission in the long-run is asymmetric involving positive price stocks to be transmitted with higher intensity compared to negative prices shocks; asymmetries in price transmission exist in the short-run as well.
\end{abstract}

Keywords: Skim Milk Powder, Asymmetric Price Transmission, Law of One Price, Nonlinear ARDL model

JEL Classification: Q11, C22

Acknowledgements: The authors gratefully acknowledge financial support from the Massey University Research Fund (MURF). They would also like to thank two anonymous referees for constructive comments. The usual caveat applies. 


\section{Introduction}

The relationships between prices in the physical space have long been a central topic in economic literature. The reason is that the strength and the pattern of price linkages may provide useful information on whether a given set of spatial markets are integrated (globalized) or segmented (localized). Under integration, price shocks in one market evoke responses in other markets. In the long-run, price shocks are fully transmitted, prices move proportionally to each other over time, and the price difference of the same commodity in any two geographically separated markets becomes equal to the transaction costs involved in transferring it from the surplus market to the deficit one (Law of One Price, henceforth LOP). On the other hand, under spatial market segmentation, the arbitrage opportunities are not fully exploited thus resulting into welfare losses (Asche, Bremnes and Wessels, 1999; Serra, Gil and Goodwin, 2006; Goshray, 2010).

In the last 30 years, the economic research on market integration has relied heavily on notions from time series analysis and, in particular, on those of integration and cointegration. A number of researchers have focused on the intensity of spatial price relationships; they have tried to verify whether the restrictions imposed by the LOP on cointegrating vectors (proportional price movements) are compatible with the real word data (e.g. Asche, Bremnes and Wessels, 1999; Dawson and Dey, 2002; Eryigit and Karaman, 2011; Emmanouilides and Fousekis, 2012). Other researchers have concentrated on the pattern of spatial price relationships. A number of alternative approaches such as the Asymmetric Vector Error Correction (AVEC), the Threshold Autoregression (TAR), the Threshold Vector Error Correction (TVEC), and the Smooth Transition Vector Error Correction (STVEC) models have been employed to capture potential short-run linearities, "inactivity bands”, and asymmetries in price transmission (e.g. Goodwin and Piggott, 2001; Abdulai, 2002; Serra, Gil and Goodwin, 2006; Milas, Otero and Panagiotidis, 2004; Goshray, 2010). ${ }^{1}$ Mayer and von Cramon-Taubadel (2004) in their seminal paper distinguish between two, not mutually exclusive, types of price transmission asymmetry: (a) the long-run (or asymmetry in magnitude) and (b) the short-run (or asymmetry in speed). In a spatial context, the former refers to the magnitude of price response at a given market conditional on the direction of a price change in another market while the latter refers to the pace of price response

\footnotetext{
${ }^{1}$ For reviews on the econometric analysis of price transmission see Frey and Manera (2007) and Hassouneh et al.(2012).
} 
at a given market conditional on the direction of a price change in another market. Econometric models such as the AVEC, the TVEC, and all others mentioned above, maintain symmetric price transmission in the long-run. However, as noted by Gonzalo and Pitarakis (2006), if the maintained hypothesis of symmetric price transmission in the long-run is not true, this may yield misleading estimates, not only for the long-run relationship between the prices at different markets but for the adjustment process that leads to it (i.e. for the speed of adjustment/the shortrun asymmetry) as well.

Against this background the objective of this article is to investigate price transmission in the international skim milk powder (henceforth SMP) markets. The trade of dairy commodities has become an increasingly important component of the international food trade in the last twenty years due to: (a) the general drive for trade liberalization through multilateral and bilateral agreements, (b) innovations in milk processing, and (c) rising per capita incomes, changing demographics and dietary patterns in a number of countries facing natural handicaps in dairy production (e.g. Beghin, 2005; Dong, 2006). The value share of milk and milk products in the global agricultural trade is close to 7\% (IDF, 2013). The SMP is the third most important, in terms of product weight, internationally traded dairy commodity (after whole milk powder and cheese).

The assessment of the degree of integration in the international SMP market presents particular interest for two main reasons. First, the SMP market is considered to be the most competitive among all international dairy commodity markets (Leong, 2014). Second, the three principal SMP producing and exporting regions (the European Union, the United States of America, and Oceania (Australia and New Zealand)) apply different trade policies with respect to the commodity. A relevant question, therefore, is whether the policy differences have an impact on the strength and the mode of price transmission from one region to another.

The empirical investigation here relies on the recently developed Nonlinear Autoregressive Distributed Lag (NARDL) model (Shin, Yu and Greenwood-Nimmo, 2014) which can accommodate for both long- and short-run transmission asymmetry offering in this way richer insights about the intensity and the pattern of spatial price linkages. The NADRL has been employed, among others, by Katrakilidis and Trachanas (2012) to analyze housing price dynamics, by Greenwood-Nimmo and Shin (2013a) to assess the effect of taxation on retail energy prices, and by Bagnai and Mongeau Ospina (2015) to evaluate price transmission 
asymmetries in the crude oil-gasoline market. To the best of our knowledge, the NARDL has not been employed so far for the analysis of spatial price transmission. Also, it appears that there have not been other published works on the integration of the international dairy commodity markets with the NARDL or with any other appropriate methodology. In what follows, section 2 presents the analytical framework and section 3 presents the data, the empirical models, and the empirical results. Section 4 offers a discussion and conclusions.

\section{The Nonlinear Autoregressive Distributed Lag Model}

The standard linear $\operatorname{ARDL}(p, q)$ cointegration model (Pesaran and Shin, 1999; Pesaran, Shin and Smith, 2001) with two series $y_{t}$ and $x_{t}(t=1,2, \ldots, \mathrm{T})$ has the following form:

$$
\Delta y_{t}=\mu+\rho y_{t-1}+\theta x_{t-1}+\gamma z_{t}+\sum_{j=1}^{p-1} \alpha_{j} \Delta y_{t-j}+\sum_{j=0}^{q-1} \pi_{j} \Delta x_{t-j}+u_{t}
$$

where $z_{t}$ is a vector of deterministic regressors (trends, seasonals, and other exogenous influences, with fixed lags) and $u_{t}$ is an iid stochastic process. Under the null hypothesis (that is, $y_{t}$ and $x_{t}$ are not cointegrated), the coefficients of lagged level of those two series in (1) are jointly zero ( $\rho=\theta=0$ ). As shown by Pesaran, Shin and Smith (2001) the null hypothesis can be tested either by means of a modified $F$-test, denominated $F_{\mathrm{PSS}}$ or (for cases where certain classical assumptions are violated) by means of a Wald-test, denominated $W_{\text {PSs. }}$. The testing procedure relies on two critical bounds; the upper and the lower one. If the empirical values of the $F_{\text {PSS }}$ (or the $W_{\text {PSS }}$ ) exceed the upper bound the null is rejected; if they lie below the lower bound, $y_{t}$ and $x_{t}$ are not cointegrated; if they lie between the critical bounds the test is inconclusive.

Alternatively, the null hypothesis can be assessed by means of the $t_{\mathrm{BDM}}$ statistic (Banerjee, Dolado and Mestre, 1998) suitable for testing $\rho=0$ (no cointegration) against $\rho<0$ (cointegration). The $t_{\mathrm{BDM}}$ test also relies on two critical bounds (the upper and the lower one). If the empirical value of the $t_{\mathrm{BDM}}$ statistic exceeds the upper bound, the null is rejected; if it lies below the lower bound, the null is not rejected; if it lies between the bounds the test is inconclusive.

Relative to other cointegration testing techniques the ARDL methodology has a number of advantages. First, it performs better in small samples. Second, it is more efficient than the 
standard Granger-Engle two-step approach (typically employed in the AEC, the TVEC, and the STVEC models). Third, it does not require the restrictive assumption that all the regressors are integrated of the same order allowing for the inclusion of both $I(0)$ and $I(1)$ (but not of $I(2)$ ) time series in a long-run relationship. The latter not only provides considerable flexibility but also avoids potential "pre-test bias", that is, specification of a long-run model on the basis of $I(1)$ variables only (Pesaran, Shin and Smith, 2001; Romilly, Song and Liu, 2001).

The ARDL model in (1) implies symmetric adjustment in the long-and the short-run. It becomes, therefore, inappropriate when the links between $y_{t}$ and $x_{t}$ are nonlinear (asymmetric). To account for this issue, Shin, Yu and Greenwood-Nimmo (2014) introduced the NARDL model in which $x_{t}$ is decomposed into positive and negative partial sums:

$$
x_{t}=x_{0}+x_{t}^{+}+x_{t}^{-}
$$

where

$$
x_{t}^{+}=\sum_{j=1}^{t} \Delta x_{j=1}^{+}=\sum_{j=1}^{t} \max \left(\Delta x_{j}, 0\right) \text { and } x_{t}^{-}=\sum_{j=1}^{t} \Delta x_{j=1}^{-}=\sum_{j=1}^{t} \max \left(\Delta x_{j}, 0\right)
$$

Then the long-run equilibrium relationship can be expressed as:

$$
y_{t}=\beta^{+} x_{t}^{+}+\beta^{-} x_{t}^{-}+u_{t}
$$

where $\beta^{+}$and $\beta^{-}$are the asymmetric long-run parameters associated with positive and negative changes in $x_{t}$, respectively. ${ }^{2}$ Combining (4) and (1) one obtains the NARDL $(p, q)$ model:

$$
\Delta y_{t}=\mu+\rho y_{t-1}+\theta^{+} x_{t-1}^{+}+\theta^{-} x_{t-1}^{-}+\gamma z_{t}+\sum_{j=1}^{p-1} \alpha_{j} \Delta y_{t-j}+\sum_{j=0}^{q-1}\left(\pi_{j}^{+} \Delta x_{t-j}^{+}+\pi_{j}^{-} \Delta x_{t-j}^{-}\right)+u_{t}
$$

where $\theta^{+}=-\rho / \beta^{+}$and $\theta^{-}=-\rho / \beta^{-}$.

The empirical implementation of a NARDL model is carried out in four steps. The first, is to estimate (5) by standard OLS. The second, is to verify the existence an asymmetric cointegrating relationship between the levels of the series $y_{t}, x_{t}^{+}$, and $x_{t}^{-}$. The null hypothesis of no cointegration, under the approach proposed by Shin, Yu and Greenwood-Nimmo (2014), involves $\rho=\theta^{+}=\theta^{-}=0$ and it can be tested using the $F_{\text {PSS }}$ or the $W_{\text {PSS }}$ statistic; the same hypothesis, under the approach proposed by Banerjee, Dolado and Mestre (1998), involves

\footnotetext{
${ }^{2}$ The use of positive and negative sums is consisted with zero threshold. As noted by Granger and Yoon (2002) the zero threshold makes the interpretation of the estimation results easy and natural.
} 
$\rho=0$ and it can be tested using the $t_{\mathrm{BDM}}$ statistic. The third, is to test for long- and short-run symmetry. For long-run symmetry, the relevant null hypothesis takes the form $\beta^{+}=\beta^{-}$(i.e., $\left.-\theta^{+} / \rho=-\theta^{-} / \rho\right)$ and is tested by means of a standard Wald test. For short-run symmetry, the relevant null hypothesis can take either of the following two forms, the pairwise (strong-form) symmetry requiring $\pi_{j}^{+}=\pi_{j}^{-}$for all $j=1, \ldots, q-1$ or the additive (weak-form) symmetry requiring $\sum_{j=0}^{q-1} \pi_{j}^{+}=\sum_{j=0}^{q-1} \pi_{j}^{-}$. These hypotheses are tested by means of a standard Wald test as well. Provided that there is asymmetry (either in the long-run or in the short-run or in both), the fourth step involves the derivation of the positive and the negative dynamic multipliers associated with unit changes in $x_{t}^{+}$and $x_{t}^{-}$. These are calculated as:

$$
m_{h}^{+}=\sum_{j=0}^{h} \frac{\partial y_{t+j}}{\partial x_{t}^{+}} \text {and } m_{h}^{-}=\sum_{j=0}^{h} \frac{\partial y_{t+j}}{\partial x_{t}^{-}} \text {with } h=0,1,2, \ldots
$$

for $x_{t}^{+}$and $x_{t}^{-}$, respectively. Note that as $h \rightarrow \infty$, then $m_{h}^{+} \rightarrow \beta^{+}$and $m_{h}^{-} \rightarrow \beta^{-}$. Depicting and analysing the paths of adjustment and/or the duration of the disequilibrium following initial positive or negative perturbations in prices, adds useful information with regard to the long- and short-run patterns of asymmetry.

\section{The Data, the Empirical Models, and the Empirical Results}

The data for the empirical investigation are monthly wholesale prices of SMP (in\$1000 per ton). They have been obtained from DairyCo ${ }^{3}$ and they refer to the period January 2003 to February 2015. The EU, the USA, and Oceania with shares of 30.7\%, 25.8\%, and $18.8 \%$, respectively are the three principal SMP producing regions in the World. They are at the same time the three principal exporters; taken together, they accounted for more than $79.8 \%$ of the World SMP exports in 2012-14. Almost 75\% of the Oceania's exports originate from New Zealand. The principal import markets for SMP are Mexico, China, and North Africa. Table 1 provides information about the international trade of SMP in the recent years.

\section{[Table 1 about here]}

The SMP is considered to be a highly suitable dairy commodity for emerging markets with low purchasing power. It is used for the recombination of milk products and for other

\footnotetext{
${ }^{3}$ www.dairyco.org.uk/market-information (accessed 4 April 2015).
} 
applications in the food industry as well. The demand for SMP in developed countries has been stagnating in recent years. Therefore, the growth in SMP production has been stimulated almost exclusively from exports to countries where not enough freshly produced milk is available. Trade flows of SMP among the USA, the EU, and Oceania are negligible (if any); market integration in this case may be achieved indirectly (that means, from the fact that the three principal producing regions compete for customers in the international SMP market).

Fig. 1 presents the natural logarithms of SMP prices for the United States (US), for the European Union (EU), and for Oceania (OC). On average, the USA has been the region with the lowest price (2622) and Oceania has been the region with the highest price (2823). The three series tend generally to move together providing, thus, an indication that price shocks are transmitted from one SMP producing region to the other(s).

[Fig. 1 about here]

Table 2presents the Ng and Perron (2001) unit root tests on the (log) levels of prices and on their first differences. The results suggest that the SMP (log) prices in the EU and Oceania are $I(1)$, while the SMP (log) prices in the US are $I(0)$ at the $10 \%$ and at the $1 \%$, significance level, for the constant and for the constant and time trend test specification, respectively. However, a visual inspection of the series (Fig. 1) indicates that the series might have been affected by the presence of multiple structural breaks. Accordingly, we additionally apply the powerful CarrionI-Silvestre, Kim, and Perron (2009) unit root test which allows for up to five breaks in the level and in the slope of the trend function, both under the null and under the alternative hypotheses. The results presented in Table 3 provide evidence that all three SMP (log) prices are first difference stationary, i.e. $I(1)$.

\section{[Tables 2 and 3about here]}

An important issue in the empirical investigation of price transmission is the selection of the so-called causal markets (i.e. markets at which prices are established/markets from which price shocks emanate). In a number of earlier studies the direction of causality was defined ad hoc based on certain characteristics of the market or on some theoretical model (e.g. Kinnucan and Forker, 1987; Lass, 2005). In others, the casual market was identified by employing some type of causality or exogeneity test (e.g. Tiffin and Dawson, 2000; Goodwin and Piggott, 2001). That approach is adopted here as well. In particular, to determine the causal market we employ the leveraged bootstrap simulation test of causality proposed by Hacker and Hatemi-J (2012) 
which produces critical values that are not sensitive to non-normal errors and to time-varying volatility. The (bivariate) test has been applied to three pairs of prices, namely, (EU, OC), (EU, US) and (OC, US). Table 4 presents the results. It appears that there is uni-directional causality from the EU to Oceania and from the EU to the USA, and bi-directional causality for the Oceania and the USA. The above suggest that we have to test for (potentially) asymmetric cointegration using four NARDL models. For the first, the endogenous is the price in Oceania and the exogenous (forcing) is the price in the USA; for the second, the endogenous is the price in Oceania and the forcing is the price in the EU; for the third, the endogenous is the price in the USA and the exogenous is the price in EU; and for the fourth, the endogenous is the price in the USA and the forcing is the price in Oceania.

\section{[Table 4 about here]}

The estimated NARDL $(p, q)$ models here have the following general forms: ${ }^{4}$

(Oceania and USA, with USA forcing)

$$
\Delta O C_{t}=\mu+\rho O C_{t-1}+\theta^{+} U S_{t-1}^{+}+\theta^{-} U S_{t-1}^{-}+\sum_{j=1}^{p-1} \alpha_{j} \Delta O C_{t-j}+\sum_{j=0}^{q-1}\left(\pi_{j}^{+} \Delta U S_{j-1}^{+}+\pi_{j}^{-} \Delta U S_{j-1}^{-}\right)+u_{t}
$$

(Oceania and EU, with EU forcing)

$$
\Delta O C_{t}=\mu+\rho O C_{t-1}+\theta^{+} E U_{t-1}^{+}+\theta^{-} E U_{t-1}^{-}+\sum_{j=1}^{p-1} \alpha_{j} \Delta O C_{t-j}+\sum_{j=0}^{q-1}\left(\pi_{j}^{+} \Delta E U_{j-1}^{+}+\pi_{j}^{-} \Delta E U_{j-1}^{-}\right)+u_{t}
$$

(USA and EU, with EU forcing)

$$
\Delta U S_{t}=\mu+\rho U S_{t-1}+\theta^{+} E U_{t-1}^{+}+\theta^{-} E U_{t-1}^{-}+\sum_{j=1}^{p-1} \alpha_{j} \Delta U S_{t-j}+\sum_{j=0}^{q-1}\left(\pi_{j}^{+} \Delta E U_{j-1}^{+}+\pi_{j}^{-} \Delta E U_{j-1}^{-}\right)+u_{t}
$$

(USA and Oceania, with Oceania forcing)

$$
\Delta U S_{t}=\mu+\rho U S_{t-1}+\theta^{+} O C_{t-1}^{+}+\theta^{-} O C_{t-1}^{-}+\sum_{j=1}^{p-1} \alpha_{j} \Delta U S_{t-j}+\sum_{j=0}^{q-1}\left(\pi_{j}^{+} \Delta O C_{j-1}^{+}+\pi_{j}^{-} \Delta O C_{j-1}^{-}\right)+u_{t}
$$

The lag length in each case has been determined adopting a general-to-specific approach (e.g. Greenwood-Nimmo and Shin, 2013a; Shin, Yu and Greenwood-Nimmo, 2014). In particular, the preferred specification in each case has been selected by starting with max $q=$ max $p=12$ (because observations are monthly) and dropping all the insignificant regressors with

\footnotetext{
${ }^{4}$ Examining price transmission and the LOP using bivariate relationships is a common practice in empirical works (e.g. Serra, Gil and Goodwin, 2006; Ghoshray, 2010; Emmanouilides and Fousekis, 2012).
} 
a $5 \%$ unidirectional decision rule; the inclusion of insignificant lags is likely to lead to inaccuracies in the estimation and may introduce noise into the dynamic multipliers.

Table 5 (columns (a), (c), (e), and (f)) presents the test results for asymmetric cointegration. For all four models, the $F_{\mathrm{PSS}}$, the $W_{\mathrm{PSS}}$ and the $t_{\mathrm{BDM}}$ statistics reject the null hypothesis of no cointegration at any reasonable level of significance. Note that, following Shin, Yu and Greenwood-Nimmo (2014), we have adopted a conservative approach to the choice of critical values by employing $k=1$ in testing for the null (i.e., a higher critical value).

\section{[Table 5 about here]}

Table 6 (columns (a), (c), (e), and (f)) presents the test results for long- and short-run symmetry. ${ }^{5}$ For the pair (OC, US) with US forcing, the Wald test fails to reject the null of longrun symmetry but it is rejects the null of short-run symmetry; for the pair (OC, EU) with EU forcing, the Wald test strongly rejects the null of long-run symmetry but it fails to reject the null of short-run symmetry. For the pairs (US, EU) with EU forcing, and (US, OC) with Oceania forcing, the Wald test strongly rejects both long- and short-run symmetry.

[Table 6 about here]

Greenwood-Nimmo et al.(2013b) suggest that in cases where long- or short-run symmetry turns out to be consistent with the real world data, the general NARDL model should be re-estimated with the respective symmetry condition imposed in order to avoid potential misspecification of either the long-run relationship or of the short-run model dynamics. That suggestion has been followed here as well. In particular, the model pair (OC, US) with US forcing has been re-estimated with the long-run symmetry imposed as:

$$
\Delta O C_{t}=\mu+\rho O C_{t-1}+\theta U S_{t-1}+\sum_{j=1}^{p-1} \alpha_{j} \Delta O C_{t-j}+\sum_{j=0}^{q-1}\left(\pi_{j}^{+} \Delta U S_{j-1}^{+}+\pi_{j}^{-} \Delta U S_{j-1}^{-}\right)+u_{t}
$$

while the model (OC, EU) with the EU forcing has been re-estimated with the short-run symmetry imposed as:

$$
\Delta O C_{t}=\mu+\rho O C_{t-1}+\theta^{+} E U_{t-1}^{+}+\theta^{-} E U_{t-1}^{-}+\sum_{j=1}^{p-1} \alpha_{j} \Delta O C_{t-j}+\sum_{j=0}^{q-1} \pi_{j} \Delta E U_{j-1}+u_{t}
$$

Columns (b) and (d) in Table 5 present the results of the asymmetric cointegration test for models (11) and (12), respectively. In both cases the null of no cointegration is strongly rejected

\footnotetext{
${ }^{5}$ As the earlier relevant empirical works employing the NARDL model, we consider the less restrictive additive case of short-run symmetry, i.e. the additive (weak-form) symmetry requiring $\sum_{j=0}^{q-1} \pi_{j}^{+}=\sum_{j=0}^{q-1} \pi_{j}^{-}$.
} 
by the data. Columns (b) and (d) in Table (6) present the results of the test of short-run symmetry conditional on long-run symmetry for model (11) and the results of the test of long-run symmetry conditional on short-run symmetry for model (12), respectively. Again, the respective null hypotheses are rejected.

Table 7 presents the parameter estimates of the models selected from the barrage of tests applied above. The explanatory power in every case is relatively high and the diagnostic tests are quite satisfactory. Table 8 presents the estimates of the long-run, symmetric and asymmetric, coefficients (i.e. the price transmission elasticities). Under the LOP, positive and negative price shocks are fully transmitted from one spatial market to the other. Here, given that the empirical models are estimated on the natural logs of prices, the LOP requires both symmetry as well as unitary transmission elasticities. For the price pairs that the long-run symmetry is rejected, the LOP is rejected (by definition). We, therefore, have tested for the LOP only for the pair (OC, US) with US forcing; the $p$-value from the respective Wald statistic is 0.013 indicating that the LOP does not hold for that pair also.

\section{[Tables 7 and 8 about here]}

Although the LOP has been rejected everywhere, the elasticities of price transmission are quite high ranging from 0.811 to 1.006 , thus pointing to a considerably integrated market. There are two possible reasons for that. First, since the early 1990s the EU and the USA adopted a step by step movement to market system for dairy commodities (gradual reduction of export restitutions and reference prices); moreover, the USA emerged as a very important player in SMP markets by the mid-2000s (Thiele, Richarts and Burchardi, 2013). Second, the SMP is largely sold in international markets as a bulk commodity. The increase in the intensity of competition and the absence of differentiation are expected a priori to facilitate spatial price transmission. Based on the values of the long-run coefficients, the pair (US, OC) with OC forcing and the pair (OC, EU) with EU forcing exhibit the strongest degrees of co-movement, while the pair (OC, US)with US forcing the weakest one.

For the pair (OC, EU) with EU forcing, $\beta_{O C, E U}^{+}$equals 0.955 and $\beta_{O C, E U}^{-}$equals 0.900 suggesting that a $1 \%$ increase (decrease) in the EU price leads to a $0.955 \%(0.990 \%)$ increase (decrease) in the OC price; positive price shocks from EU are transmitted to Oceania with higher intensity than negative shocks. In particular, the transmission elasticity of positive shocks is $5.5 \%$ percent larger than that of negative price shocks. The same finding (higher intensity of 
transmission for the positive price shocks) applies to the other two cases where the long-run transmission is asymmetric. In particular, the price transmission elasticities of positive shocks for the pairs (US, EU) with EU forcing and (US, OC) with OC forcing are 8.3\% and 5.9\% higher than those of negative type shocks, respectively.

One possible reason behind this pattern of transmission asymmetry is that the international trade of SMP has been growing at a very fast pace over the time period considered in this article. As matter of fact, SMP exports have increased from less than 1 million tons a year in the early 2000s to 1.8 million tons recently. In times when import demand and trade are booming and stocks are tight, exporters have a stronger incentive to match a price increase from their competitors rather than a price decrease.

The literature on spatial market integration (e.g. Meyer and Von Cramon-Taubadel, 2004; Emmanouilides and Fousekis, 2012) points to two main factors behind long-run asymmetric price transmission and failure of the LOP. These are asymmetric information between central (hub) and peripheral (spoke) markets and trade distortions. The former is not likely to be applicable here since the three regions considered are the principal producers and exporters of SMP. The latter, however, appears to be relevant because while New Zealand and Australia are strong supporters of free trade for dairy commodities, the EU and the USA still apply tradedistorting policies such as Tariff Rate Quotas (TRQs), intervention prices, and private storage aid (e.g. Thiele, Richarts and Burchardi, 2013; Carter, 2014; FAS, 2015). These policy schemes generate price floors. The asymmetries in price transmission, therefore, may be simply picking up threshold effects.

The presence of price floors probably explains the empirical finding that the pattern of price transmission for the pair USA and Oceania depends on the forcing variable. In particular, a price decrease in Oceania is transmitted to the US with lower intensity compared to a price increase because the USA protects its domestic market through the application of TQRs. When, however, the USA is forcing the sign of the price change does not matter since Australia and New Zealand practice free trade.

As noted in the Introduction when the LOP fails, either because the transmission elasticities are different from 1 or because the long-run price transmission is asymmetric, there is a loss in economic efficiency. Following the Uruguay Round Agreement on Agriculture (1994) both the USA and the EU replaced explicit dairy import quotas with TRQs, reduced the higher- 
tier rates, and increased gradually the quantities subject to lower-tier rates. Although considerable progress has been made over the last 20 years, the complete elimination of protection of dairy commodities in those two regions remains a hot issue in the policy domain. In the Autumn of 2015, the EU Commission objected to an upwards revision of the intervention price for SMP despite the strong pressure exercised by the Agricultural Committee of the EU Parliament, dairy farmers unions, and certain large member states such as France (Aline, 2015). On the other side of the Atlantic, the 2014 Farm Bill provided a potentially substantial boost to dairy subsidies charting in this way a path diametrically opposite to that initiated by the WTO's Doha round in 2011 (Carter, 2014).

Figs 2, 3, 4 and 5 present the dynamic multipliers for the price pairs considered. These allow us to trace the evolution of a price at a given SMP market following a shock to a price at another SMP market, providing in this way a picture of the path to the new equilibrium. What is transpired from Figs 2 to 5 is consistent with the magnitude and the sign of the short-and longrun coefficients reported in Tables (7) and (8).

Specifically, for the pair (OC, US) with US forcing (Fig. 2), the positive price shocks in the short run are transmitted with higher intensity than the negative ones. The equilibrium adjustment is achieved after nearly 2 years while the long-run effect, as depicted by the asymmetry line, of an increase in the US on the OC price, is symmetrical to that of a decrease. The behaviour of the dynamic multiplier is consistent with sizeable short-run asymmetry and long-run symmetry.

[Fig. 2 about here]

For the pair (OC, EU) with EU forcing (Fig. 3), we observe that OC prices respond at almost the same rate in the short-run, to EU increases and decreases. The equilibrium correction is achieved within 1 year while the long-run effect of an increase in the EU on the OC price is larger than that of a decrease. The behaviour of the dynamic multiplier is consistent with shortrun symmetry and sizable long-run asymmetry.

\section{[Fig. 3 about here]}

For the pair (US, EU) with EU forcing (Fig. 4), there is again asymmetric transmission in the short-run with the equilibrium correction achieved after nearly 2 years, while the long-run effect of an increase in the EU on the US price is significantly larger than that of a decrease. The behaviour of the dynamic multiplier is consistent with long- and short-run asymmetry. 
[Fig. 4 about here]

Finally, for the pair (US, OC) with OC forcing (Fig. 5), the effect of negative shocks is stronger than that of the positive in the short-run and equilibrium adjustment is achieved in about 22 months. The long-run effect of an increase in the OC on the US price is slightly larger than that of a decrease. The behaviour of the dynamic multiplier is consistent with long- and short-run asymmetry.

[Fig. 5 about here]

\section{Conclusions}

Spatial price relationships contain information on the performance (functioning) of geographically separated markets and have long attracted the attention of both economists and policy makers. In this context, the present work investigates the strength and the pattern of spatial price linkages in the SMP markets. The empirical analysis relies on monthly wholesale

price data from the three principal SMP producing and exporting regions (the USA, the EU, and Oceania) and on the Nonlinear Autoregressive Distributed Lag (NARDL) model. The major advantage of the NARDL approach relative to competing methodological approaches is that it accommodates both short- and long-run asymmetry and, in addition, it allows testing for the validity of the Law of One Price.

The empirical results of this article suggest that:

(a) The three geographically separated SMP producing regions considered here are well integrated in the sense that wholesale prices in them are linked with stable long-run relationships and that the long-run transmission elasticities of price shocks from one region to the other are generally high. The intensification of SMP trade over the recent years and the lack of differentiation may explain the high degree of integration.

(b) Despite the satisfactory performance in terms of price transmission, the SMP markets are not (strictly speaking) efficient. The condition for the LOP (proportional co-movement of price shocks) is not satisfied for any of the pairs of regions examined. The dominant pattern of transmission in the long-run is the one in which positive price shocks are transmitted with higher intensity compared with the negative price shocks. It likely that the strong and uninterrupted expansion of SMP markets and exports and the application of TRQs and intervention prices from the EU and the USA are the key factors behind this finding. 
(c) Price transmission asymmetries exist in the short-run as well. The time required for equilibrium adjustment ranges from 1 to 2 years. Considering the speed of price adjustment as another indicator of the degree of market integration one may conclude that the pair of regions EU and Oceania (where adjustment is completed relatively fast) is more integrated than the pairs EU and the USA, and the USA and Oceania.

The deepening of integration of the global SMP markets, in the near future, will be determined by a number of factors. First, the rate of economic growth in emerging economies. Second, the trade policies of major SMP producers such as the EU and the USA. Third, the impact of the removal (effective since April 2015) of the EU milk production quota on the supply of milk and of dairy commodities. In anticipation of the quota's abolition substantial amounts have been invested at the EU level to powder drying facilities for export markets (Dairy Australia, 2013). Fourth, the effort by major SMP importers (e.g. China) to build self-sufficiency in dairy commodities. Last but not least, the bilateral and multilateral trade agreements which have been already concluded or are currently under consideration. Among them stand out the free trade agreement between the EU and Japan and the Transpacific Partnership Agreement (TPPA), signatories of which are 12 Pacific Rim countries including principal exporters (Oceania and the USA) and important importers (e.g. Mexico, Malaysia, and Vietnam).

\section{References}

Abdulai, A. 2002. "Spatial Price Transmission and Asymmetry in the Ghanaian Maize Market." Journal of Development Economics 63 (2): 327-349. doi: 10.1016/S0304-3878(00)001152.

Aline, R. 2015. "Milk Crisis Drives Wedge Between France and Germany.” EurActiv.fr, September 11. Accessed 15 November 2015. http://www.euractiv.com/section/agriculturefood/news/milk-crisis-drives-wedge-between-france-and-germany/

Asche, F., H. Bremnes, and C. Wessels. 1999. "Product Aggregation, Market Integration, and Relationships between Prices.” American Journal of Agricultural Economics 81 (3): 56881. doi: $10.2307 / 1244016$.

Bagnai, A. and C.A., Mongeau Ospina. 2015. "Long- and Short-Run Price Asymmetries and Hysteresis in the Italian Gasoline Market.” Energy Policy 78: 41-50.

doi:10.1016/j.enpol.2014.12.017. 
Banerjee, A., J. Dolado, and R. Mestre. 1998. "Error-correction Mechanism Tests for Cointegration in a Single-Equation Framework.” Journal of Time Series Analysis 19 (3): 267-283. doi: 10.1111/1467-9892.00091

Beghin, J. 2005. "Dairy Markets in Asia. An Overview of Recent Findings and Implications." Briefing Paper 05-BP-47. Centre of Agricultural and Rural Development, Iowa State University. http://www.card.iastate.edu/publications/dbs/pdffiles/05bp47.pdf

Carrion-i-Silvestre, J.L., D. Kim, and P. Perron. 2009. “GLS-based Unit Root Tests with Multiple Structural Breaks under Both the Null and the Alternative Hypotheses.” Econometric Theory 25: 1754-1792. doi: http://dx.doi.org/10.1017/S0266466609990326

Carter, C. 2014. “Some Trade Implications of the 2014 Agricultural Act.” Choices 29(3): 1-4. http://ageconsearch.umn.edu/bitstream/186907/2/cmsarticle_387.pdf

Dairy Australia 2013. “Dairy Situation And Outlook.” No 9, May. http://www.dairyaustralia.com.au/ /media/Documents/Stats\%20and\%20markets/S\%20and \%20O/May\%202013/Dairy\%20Situation\%20and\%20Outlook\%20May\%202013\%20\%20Full\%20Report.pdf

Dawson, P., and P. Dey. 2002. “Testing for the Law of One Price: Rice Market Integration in Bangladesh.” Journal of International Development 14 (4): 473-484. doi: 10.1002/jid.888.

Dong, F. 2006. "The Outlook for Asian Dairy Markets: The Role of Demographics, Income, and Prices.” Food Policy 31 (3): 260-271. doi:10.1016/j.foodpol.2006.02.007

Emmanouilides, C., and P. Fousekis. 2012. "Testing for the LOP under Non Linearity: An Application to Four Major EU Markets.” Agricultural Economics 43 (6): 715-723. doi: 10.1111/j.1574-0862.2012.00614.X.

Eryigit, K.Y., and S. Karaman. 2011. "Testing for Spatial Market Integration and the Law of One Price in Turkish Wheat Markets.” Quality and Quantity 45 (6): 1519-1530. doi: 10.1007/s11135-010-9320-1

FAS - Foreign Agricultural Service, United States Department of Agriculture (2015). Dairy Import Licensing Program. Accessed 8 March 2016. http://www.fas.usda.gov/programs/dairy-import-licensing-program

Frey, G., and F. Manera. 2007. "Econometric Models of Asymmetric Price Transmission.” Journal of Economic Surveys 21 (2): 349-415. doi: 10.1111/j.1467-6419.2007.00507.x.

Ghoshray, A. 2010. “The Extent of the World Coffee Market.” Bulletin of Economic Research 62 (1): 97-107. doi: 10.1111/j.1467-8586.2009.00318.x.

Gonzalo, J., and J. Pitarakis. 2006. “Threshold Effects in Cointegrating Relationships.” Oxford Bulletin of Economics and Statistics, 68 (Supplement 1): 813-833. doi: 10.1111/j.14680084.2006.00458.x.

Goodwin, B., and N. Piggott. 2001. "Spatial Market Integration in the Presence of Threshold Effects.” American Journal of Agricultural Economics 83 (2): 302-317. doi: 10.1111/00029092.00157

Granger, W., and G. Yoon. 2002. “Hidden Cointegration.” Discussion Paper 2002-02. San Diego, University Of California. 
Greenwood-Nimmo, M., and Y. Shin. 2013a. "Taxation and the Asymmetric Adjustment of Selected Retail Energy Prices in the UK.” Economics Letters 121 (3). 411-416. doi:10.1016/j.econlet.2013.09.020

Greenwood-Nimmo, M., Y. Shin, T. Van Treeck and B. Yu. 2013b. "The Decoupling of Monetary Policy from Long-Term Rates in the US During the Great Moderation.” Working Paper. http://papers.ssrn.com/sol3/papers.cfm?abstract_id=1894621

Hacker, R.S., and A. Hatemi-J. 2010. "HHcte: GAUSS Module to Apply a Bootstrap Test for Causality with Endogenous Lag Order.” Statistical Software Components No. G00012, Boston College Department of Economics. http://fmwww.bc.edu/repec/bocode/h/HHcte.prg

Hacker, R.S., and A. Hatemi-J. 2012. "A Bootstrap Test for Causality with Endogenous Lag Length Choice: Theory and Application in Finance.” Journal of Economic Studies 39 (2). 144-160. http://dx.doi.org/10.1108/01443581211222635.

Hassouneh, I., S. von Cramon-Taubadel, T. Serra, J.M. Gil. 2012. "Recent Developments in the Econometric Analysis of Price Transmission.” Working Paper No. 2. Transparency of Food Pricing. http://www.transfop.eu/media/universityofexeter/businessschool/documents/centres/transfo p/recent_developments_in_economtric_pt.pdf

International Dairy Federation-IDF (2013). The Economic Importance of Dairy. http://www.idfgermany.com/fileadmin/user_upload/idf-germany/download/14-IDF-Factsheet-Theeconomic-importance-of-dairying.pdf

Katrakilidis, C., and E. Trachanas. 2012. "What Drives Housing Price Dynamics in Greece? New Evidence from Asymmetric ARDL Cointegration.” Economic Modelling 29 (4): 1064-1069. doi:10.1016/j.econmod.2012.03.029

Kinnucan, H.W., and O.D. Forker. 1987. "Asymmetry in Farm-Retail Price Transmission for Major Dairy Products.” American Journal of Agricultural Economics 69 (2): 285-292. doi: $10.2307 / 1242278$.

Lass, D. 2005. "Asymmetric Response of Retail Milk Prices in the Northeast Revisited.” Agribusiness 21 (4): 493-508. doi: 10.1002/agr.20061

Leong, T. 2014. “Global Dairy Players - New Zealand.” AgriHQ Academy. September 22. Accessed 20 May 2015. http://academy.farmersweekly.co.nz/Courses/Dairy/Global-dairyplayers/Global-dairy-players-New-Zealand

Meyer, J., and S. von Cramon-Taubadel. 2004. "Asymmetric Price Transmission: A Survey.” Journal of Agricultural Economics 55 (3): 581-611. doi: 10.1111/j.14779552.2004.tb00116.x.

Milas, C., J. Otero, and T. Panagiotidis. 2004. "Forecasting the Spot Prices of Various Coffee Types Using Linear and Non-Linear Error Correction Models.” International Journal of Finance and Economics 9 (3): 277-288. doi: 10.1002/ijfe.245.

Ng, S., and P. Perron. 2001. "Lag selection and the construction of unit root tests with good size and power.” Econometrica 69: 1519-1554. doi: 10.1111/1468-0262.00256 
OECD-FAO 2015. “Agricultural Outlook 2015-2024.” OECD Publishing. Accessed 8 March 2016. http://www.fao.org/3/a-i4738e.pdf

Pesaran, B., and M.H. Pesaran. 2009. Time Series Econometrics using Microfit 5.0. New York: Oxford University Press.

Pesaran, M. H., and Y. Shin. 1999. "An Autoregressive Distributed Lag Modeling Approach to Cointegration Analysis." In Econometrics and Economic Theory in the 20th Century: The Ragnar Frisch Centennial Symposium, edited by S. Strøm. Cambridge: Cambridge University Press.

Pesaran, M.H., Y. Shin, and R. Smith. 2001. "Bounds Testing Approaches to the Analysis of Level Relationships.” Journal of Applied Econometrics, 16 (3): 289-326. doi: 10.1002/jae.616

Romilly, P., H. Song, and X. Liu. 2001. "Car Ownership and Use in Britain: A Comparison of the Empirical Results of Alternative Cointegration Estimation Methods and Forecasts." Applied Economics 33 (4): 1803-1818. doi: 10.1080/00036840011021708.

Serra, T., J. Gil, and B. Goodwin. 2006. "Local Polynomial Fitting and Spatial Price Relationship: Price Transmission in EU Pork Markets.” European Review of Agricultural Economics 33 (3): 415-436. doi: 10.1093/erae/jbl013.

Shin, Y., B. Yu, and M. Greenwood-Nimmo. 2014. "Modelling Asymmetric Cointegration and Dynamic Multipliers in a Nonlinear ARDL Framework." In Festschrift in Honor of Peter Schmidt: Econometric Methods and Applications, edited by W. C. Horrace and R. C. Sickles. New York: Springer Science And Business Media, 281-314.

Thiele, H., E. Richarts, and H. Burchardi. 2013. "Economic Analysis of Dairy Sector Development Beyond 2015: Trade, Exports and World Market Integration.” University of Applied Sciences Kiel. Accessed 7 May 2015. http://future.aae.wisc.edu/publications/Economic_Analysis_EU_dairy_Sector_Beyond_201 5.pdf

Tiffin, R., and P. Dawson. 2000. "Structural Breaks, Cointegration, and the Farm-Retail Price Spread for Lamb.” Applied Economics 32 (10): 1281-1286. doi: 10.1080/000368400404434. 
Table 1. SMP exports and imports averages, 2012-2014

\begin{tabular}{lllll} 
Exports & & & & \\
\hline Region/Country & World & USA & EU & Oceania \\
\hline 1000 tons & 1977 & 503 & 515 & 561 \\
$\%$ & 100 & 25.8 & 26.7 & 30.1 \\
\hline & & & & \\
Imports & & & & \\
\hline Region/Country & World & Mexico & China & North Africa \\
\hline 1000 tons & 1947 & 224 & 222 & 203 \\
$\%$ & 100 & 11.5 & 11.4 & 10.3 \\
\hline
\end{tabular}

Source: OECD-FAO Agricultural Outlook (2015) 
Table 2. Ng-Perron (2001) unit root tests

Ng-Perron statistics (constant only)

\begin{tabular}{llllll}
\hline Variables & $M Z_{a}^{G L S}$ & $M Z_{t}^{G L S}$ & $M S B^{G L S}$ & $M P_{T}^{G L S}$ & $k$ \\
\hline$E U$ & -3.761 & -1.358 & 0.361 & 6.520 & 1 \\
$O C$ & -3.744 & -1.339 & 0.357 & 6.559 & 1 \\
$U S$ & $-7.434^{*}$ & $-1.921^{*}$ & $0.258^{*}$ & $3.321^{*}$ & 1 \\
$\Delta E U$ & $-57.852^{* * *}$ & $-5.321^{* * *}$ & $0.091^{* * *}$ & $0.559^{* * *}$ & 0 \\
$\Delta O C$ & $-48.645^{* * *}$ & $-4.923^{* * *}$ & $0.101^{* * *}$ & $0.525^{* * *}$ & 0 \\
$\Delta U S$ & $-42.264^{* * *}$ & $-4.594^{* * *}$ & $0.108^{* * *}$ & $0.586^{* * *}$ & 0 \\
\hline
\end{tabular}

Critical values (constant only)

\begin{tabular}{lllll}
\hline $1 \%$ & -13.80 & -2.58 & 0.174 & 1.78 \\
$5 \%$ & -8.10 & -1.98 & 0.233 & 3.17 \\
$10 \%$ & -5.70 & -1.62 & 0.275 & 4.45 \\
\hline
\end{tabular}

Ng-Perron statistics (constant and trend)

\begin{tabular}{llllll}
\hline Variables & $M Z_{a}^{G L S}$ & $M Z_{t}^{G L S}$ & $M S B^{G L S}$ & $M P_{T}^{G L S}$ & $k$ \\
\hline$E U$ & -13.031 & -2.402 & 0.184 & 7.838 & 1 \\
$O C$ & -15.194 & -2.638 & 0.173 & 6.701 & 1 \\
$U S$ & $-27.583^{* * *}$ & $-3.601^{* * *}$ & $0.130^{* * *}$ & $3.962^{* * *}$ & 1 \\
$\Delta E U$ & $-56.689^{* * *}$ & $-5.283^{* * *}$ & $0.093^{* * *}$ & $1.800^{* * *}$ & 0 \\
$\Delta O C$ & $-54.657^{* * *}$ & $-5.196^{* * *}$ & $0.095^{* * *}$ & $1.817^{* * *}$ & 0 \\
$\Delta U S$ & $-42.618^{* * *}$ & $-4.615^{* * *}$ & $0.108^{* * *}$ & $2.140^{* * *}$ & 0 \\
\hline
\end{tabular}

Critical values (constant and trend)

\begin{tabular}{lllll}
\hline $1 \%$ & -23.80 & -3.42 & 0.143 & 4.03 \\
$5 \%$ & -17.30 & -2.91 & 0.168 & 5.48 \\
$10 \%$ & -14.20 & -2.62 & 0.185 & 6.67 \\
\hline
\end{tabular}

For the $M S B^{G L S}$ and $M P_{T}^{G L S}$ tests, the null hypothesis is rejected in favour of stationarity when the estimated statistic is smaller than the critical value.

$k$ denotes the optimal lag length. It has been chosen on the basis of the Schwarz Information Criterion starting with max 6 lags.

The critical values are from $\mathrm{Ng}$ and Perron (2001).

The estimation and tests have been conducted using EViews 9.0. *** and * denote the rejection of the null of a unit root at the $1 \%$ and $10 \%$ significance level, respectively. 
Table 3. Carrion-I-Silvestre, Kim, and Perron (2009) unit root tests with five structural breaks

\begin{tabular}{llllll}
\hline Variable & $M Z_{a}^{G L S}$ & $M Z_{t}^{G L S}$ & $M S B^{G L S}$ & $M P_{T}^{G L S}$ & Break dates \\
\hline$E U$ & -13.335 & -2.461 & 0.184 & 28.106 & 2006:07; 2007:10; 2009:03; 2010:12; 2012:07 \\
& $(-44.818)$ & $(-4.732)$ & $(0.104)$ & $(8.323)$ & \\
OC & -32.609 & -4.035 & 0.123 & 12.233 & $2005: 12 ; 2007: 03 ; 2009: 02 ; 2011: 06 ; 2013: 11$ \\
& $(-45.401)$ & $(-4.772)$ & $(0.104)$ & $(8.665)$ & \\
\multirow{2}{*}{$U S$} & -34.958 & -4.168 & 0.119 & 10.802 & $2005: 12 ; 2007: 03 ; 2008: 08 ; 2011: 10 ; 2013: 11$ \\
& $(-44.367)$ & $(-4.720)$ & $(0.105)$ & $(8.356)$ & \\
$\Delta E U$ & $-54.574^{* *}$ & $-5.156^{* *}$ & $0.094^{* *}$ & $7.858^{* *}$ & $2006: 09 ; 2007: 12 ; 2009: 11 ; 2011: 02 ; 2012: 05$ \\
& $(-45.149)$ & $(-4.735)$ & $(0.104)$ & $(8.788)$ & \\
\multirow{2}{*}{$\Delta O C$} & $-46.838^{* *}$ & $-4.835^{* *}$ & $0.103^{* *}$ & $8.281^{* *}$ & $2006: 04 ; 2007: 07 ; 2008: 11 ; 2011: 02 ; 2013: 04$ \\
& $(-45.038)$ & $(-4.750)$ & $(0.104)$ & $(8.505)$ & \\
\multirow{2}{*}{$\Delta U S$} & $-47.472^{* *}$ & $-4.851^{* *}$ & $0.102^{* *}$ & 9.050 & $2004: 05 ; 2006: 02 ; 2007: 06 ; 2009: 12 ; 2013: 05$ \\
& $(-46.504)$ & $(-4.819)$ & $(0.103)$ & $(8.882)$ & \\
\hline
\end{tabular}

For the $M P_{T}^{G L S}$ and $M S B^{G L S}$ tests, the null hypothesis is rejected in favour of stationarity when the estimated statistic is smaller than the critical value.

The optimal lag length has been chosen on the basis of the Schwarz Information Criterion starting with max 6 lags.

Critical values at the 5\% significance level are obtained from simulations using 1000 steps to approximate the Wiener process and 10,000 replications, and are displayed in parentheses.

The tests have been conducted using a program code written in GAUSS, produced by Carrion-I-Silvestre. ** denotes rejection of the null of a unit root at the $5 \%$ significance level. 
Table 4. Causality tests using the bootstrap simulation technique

\begin{tabular}{llllll}
\hline Null Hypothesis & Test Value & $\mathrm{CV}$ at $1 \%$ & $\mathrm{CV}$ at $5 \%$ & $\mathrm{CV}$ at $10 \%$ & $k$ \\
\hline$E U \neq>$ OC & $13.476^{* * *}$ & 10.254 & 6.043 & 4.649 & 2 \\
$O C \neq>$ EU & 2.950 & 9.749 & 6.022 & 4.590 & 2 \\
$U S \neq>$ EU & 0.526 & 10.054 & 6.374 & 4.843 & 2 \\
$E U \neq>$ US & $42.058^{* * *}$ & 11.230 & 6.426 & 4.979 & 2 \\
$O C \neq>$ US & $25.053^{* * *}$ & 9.985 & 6.293 & 4.756 & 2 \\
$U S \neq>$ OC & $8.511^{* *}$ & 10.264 & 6.563 & 4.899 & 2 \\
\hline
\end{tabular}

The symbol $\neq>$ means that A does not cause B.

$\mathrm{CV}$ is an abbreviation for the bootstrap critical values.

$k$ denotes the optimal lag length in each VAR model (excluding the augmentation lag). It has been selected based on the Schwarz Information Criterion, starting with max 12 lags.

The bootstrap causality tests have been conducted using 5000 simulations with a program code written in GAUSS, produced by Hacker and Hatemi-J (2010).

$* * *$ and $* *$ denote rejection of the null hypothesis at the $1 \%$ and $5 \%$ level, respectively. 
Table 5. Bounds testing for asymmetric cointegration

\begin{tabular}{|c|c|c|c|c|c|c|}
\hline & $\begin{array}{l}\text { (OC, US) } \\
\text { with US forcing }\end{array}$ & & $\begin{array}{l}\text { (OC, EU) } \\
\text { with EU forcing }\end{array}$ & & $\begin{array}{l}\text { (US, EU) } \\
\text { with EU forcing }\end{array}$ & $\begin{array}{l}\text { (US, OC) } \\
\text { with OC forcing }\end{array}$ \\
\hline Statistic & $\begin{array}{l}\text { NARDL model with } \\
\text { LR and SR asymmetry } \\
\text { (a) }\end{array}$ & $\begin{array}{l}\text { NARDL model with } \\
\text { LR symmetry imposed } \\
\text { (b) }\end{array}$ & $\begin{array}{l}\text { NARDL model with } \\
\text { LR and SR asymmetry } \\
\text { (c) }\end{array}$ & $\begin{array}{l}\text { NARDL model with } \\
\text { SR symmetry imposed } \\
\text { (d) }\end{array}$ & $\begin{array}{l}\text { NARDL model with } \\
\text { LR and SR asymmetry } \\
\text { (e) }\end{array}$ & $\begin{array}{l}\text { NARDL model with } \\
\text { LR and SR asymmetry } \\
\text { (f) }\end{array}$ \\
\hline$F_{P S S}$ & $7.21^{* *}$ & $13.13^{* * *}$ & $16.79^{* * *}$ & $11.58^{* * *}$ & $8.41^{* * *}$ & $8.03 * * *$ \\
\hline$W_{P S S}$ & $21.65^{* * *}$ & $26.27 * * *$ & $50.37 * * *$ & $34.75^{* * *}$ & $25.24 * * *$ & $24.10 * * *$ \\
\hline$t_{B D M}$ & $-4.23 * * *$ & $-4.76^{* * *}$ & $-7.07 * * *$ & $-5.84 * * *$ & $-4.93 * * *$ & $-4.26^{* * *}$ \\
\hline
\end{tabular}

For $k=1$ and at the $1 \%$ (5\%) level of significance, the pair of critical values (bounds) for the $F_{P S S}$, the $W_{P S S}$ and the $t_{B D M}$ statistics are 6.84 to 7.84 (4.94 to 5.73), 14.11 to15.63 (9.86 to11.52) and -3.43 to -3.82 (-2.86 to -3.22$)$, respectively.

The critical values have been obtained from Pesaran, Shin and Smith (2001) and Pesaran and Pesaran (2009, p. 564-565).

The estimations and tests have been conducted using Microfit 5.0and a program code written in STATA, produced by M. Sunder and retrieved from Matthew Greenwood-Nimmo'swebpage.

*** and $* *$ denote rejection of the null hypothesis of no cointegration at the $1 \%$ and $5 \%$ levels, respectively. 
Table 6. Long- and short-run symmetry tests

\begin{tabular}{|c|c|c|c|c|c|c|}
\hline & $\begin{array}{l}\text { (OC, US) } \\
\text { with US forcing }\end{array}$ & & $\begin{array}{l}(\mathbf{O C}, \mathbf{E U}) \\
\text { with EU forcing }\end{array}$ & & $\begin{array}{l}\text { (US, EU) } \\
\text { with EU forcing }\end{array}$ & $\begin{array}{l}\text { (US, OC) } \\
\text { with OC forcing }\end{array}$ \\
\hline Statistic & $\begin{array}{l}\text { NARDL model with } \\
\text { LR and SR asymmetry } \\
\text { (a) }\end{array}$ & $\begin{array}{l}\text { NARDL model with } \\
\text { LR symmetry imposed } \\
\text { (b) }\end{array}$ & $\begin{array}{l}\text { NARDL model with } \\
\text { LR and SR asymmetry } \\
\text { (c) }\end{array}$ & $\begin{array}{l}\text { NARDL model with } \\
\text { SR symmetry imposed } \\
\text { (d) }\end{array}$ & $\begin{array}{l}\text { NARDL model with } \\
\text { LR and SR asymmetry } \\
\text { (e) }\end{array}$ & $\begin{array}{l}\text { NARDL model with } \\
\text { LR and SR asymmetry } \\
\text { (f) }\end{array}$ \\
\hline$W_{L R}$ & $0.328(0.567)$ & - & $18.749 * * *(0.000)$ & $12.299 * * *(0.000)$ & $18.908 * *(0.000)$ & $6.137 * *(0.013)$ \\
\hline$W_{S R}$ & $4.781^{* *}(0.029)$ & $9.073^{* * *}(0.003)$ & $0.164(0.685)$ & - & $5.067 * *(0.024)$ & $19.785 * * *(0.000)$ \\
\hline
\end{tabular}

$W_{L R}$ refers to the Wald test for the null of long-run symmetry defined by $-\hat{\theta}^{+} / \hat{\rho}=-\hat{\theta}^{-} / \hat{\rho}$.

$W_{S R}$ refers to the Wald test for the null of the additive (weak-form) symmetry defined by $\sum_{j=0}^{q-1} \pi_{j}^{+}=\sum_{j=0}^{q-1} \pi_{j}^{-}$.

$p$-values are displayed in parentheses.

The estimations and tests have been conducted using a program code written in STATA, produced by M. Sunder and retrieved from Matthew Greenwood-Nimmo's webpage.

*** and $* *$ denote rejection of the null hypothesis of symmetry at the 1 and $5 \%$ levels, respectively. 
Table 7. NARDL estimation results

\begin{tabular}{|c|c|c|c|c|c|c|c|c|c|c|c|}
\hline \multicolumn{3}{|c|}{$\begin{array}{l}\text { (OC, US) } \\
\text { with US forcing }\end{array}$} & \multicolumn{3}{|c|}{$\begin{array}{l}\text { (OC, EU) } \\
\text { with EU forcing }\end{array}$} & \multicolumn{3}{|c|}{$\begin{array}{l}\text { (US, EU) } \\
\text { with EU forcing }\end{array}$} & \multicolumn{3}{|c|}{$\begin{array}{l}\text { (US, OC) } \\
\text { with OC forcing }\end{array}$} \\
\hline Variable & Coefficient & SE & Variable & Coefficient & SE & Variable & Coefficient & SE & Variable & Coefficient & SE \\
\hline constant & $0.360 * * *$ & 0.133 & constant & $2.032 * * *$ & 0.347 & constant & $1.304^{* * *}$ & 0.265 & constant & $1.310 * * *$ & 0.306 \\
\hline$O C_{t-1}$ & $-0.251 * * *$ & 0.052 & $O C_{t-1}$ & $-0.273 * * *$ & 0.046 & $U S_{t-1}$ & $-0.177 * * *$ & 0.035 & $U S_{t-1}$ & $-0.177 * * *$ & 0.041 \\
\hline$U S_{t-1}$ & $0.207^{* * *}$ & 0.052 & $E U_{t-1}^{+}$ & $0.261^{* * *}$ & 0.049 & $E U_{t-1}^{+}$ & $0.158^{* * *}$ & 0.033 & $O C_{t-1}^{+}$ & $0.178^{* * *}$ & 0.038 \\
\hline$\Delta O C_{t-1}$ & $0.314^{* * *}$ & 0.083 & $E U_{t-1}^{-}$ & $0.246 * * *$ & 0.048 & $E U_{t-1}^{-}$ & $0.143 * * *$ & 0.031 & $O C_{t-1}^{-}$ & $0.168^{* * *}$ & 0.037 \\
\hline$\Delta O C_{t-4}$ & $0.158 * *$ & 0.072 & $\Delta O C_{t-1}$ & 0.195 & 0.055 & $\Delta U S_{t-1}$ & $0.331^{* * *}$ & 0.055 & $\Delta U S_{t-1}$ & $0.463 * * *$ & 0.064 \\
\hline$\Delta O C_{t-7}$ & $0.209 * * *$ & 0.073 & $\Delta O C_{t-7}$ & 0.192 & 0.056 & $\Delta U S_{t-4}$ & $0.112^{* *}$ & 0.054 & $\Delta U S_{t-3}$ & $-0.244^{* * *}$ & 0.070 \\
\hline$\Delta O C_{t-10}$ & $0.172^{* *}$ & 0.085 & $\Delta E U_{t}$ & 0.644 & 0.057 & $\Delta U S_{t-8}$ & $0.212 * * *$ & 0.066 & $\Delta U S_{t-9}$ & $-0.191 * * *$ & 0.072 \\
\hline$\Delta U S_{t}^{+}$ & $0.709^{* * *}$ & 0.158 & $\Delta E U_{t-4}$ & 0.120 & 0.057 & $\Delta E U_{t}^{+}$ & $0.232^{* * *}$ & 0.075 & $\Delta U S_{t-12}$ & $-0.190 * * *$ & 0.069 \\
\hline$\Delta U S_{t}^{-}$ & $0.441^{* * *}$ & 0.123 & & & & $\Delta E U_{t-1}^{+}$ & $0.265^{* * *}$ & 0.088 & $\Delta O C_{t-1}^{+}$ & $0.200 * *$ & 0.088 \\
\hline$\Delta U S_{t-5}^{-}$ & $-0.279 * *$ & 0.134 & & & & $\Delta E U_{t-9}^{+}$ & $-0.298 * * *$ & 0.085 & $\Delta O C_{t}^{-}$ & $0.796 * * *$ & 0.091 \\
\hline \multirow[t]{3}{*}{$\Delta U S_{t-10}^{-}$} & $-0.386^{* *}$ & 0.167 & & & & $\Delta E U_{t}^{-}$ & $0.534 * * *$ & 0.078 & $\Delta O C_{t-2}^{-}$ & $-0.210 * *$ & 0.093 \\
\hline & & & & & & & & & $\Delta O C_{t-4}^{-}$ & $0.256^{* * *}$ & 0.093 \\
\hline & & & & & & & & & $\Delta O C_{t-9}^{-}$ & $0.288 * * *$ & 0.103 \\
\hline
\end{tabular}

\section{Statistics and Diagnostics}

\begin{tabular}{|c|c|c|c|c|c|c|c|}
\hline$R^{2}$ & 0.513 & $R^{2}$ & 0.689 & $R^{2}$ & 0.761 & $R^{2}$ & 0.731 \\
\hline $\bar{R}^{2}$ & 0.474 & $\bar{R}^{2}$ & 0.673 & $\bar{R}^{2}$ & 0.742 & $\bar{R}^{2}$ & 0.704 \\
\hline SC & 17.767 (0.123) & SC & 8.337 (0.758) & SC & $9.469(0.662)$ & SC & $7.933(0.790)$ \\
\hline $\mathrm{FF}$ & $0.049(0.825)$ & FF & $2.066(0.151)$ & FF & $0.010(0.917)$ & FF & $0.003(0.950)$ \\
\hline $\mathrm{ARCH}$ & $11.177(0.514)$ & ARCH & 17884 (0.119) & ARCH & $9.911(0.624)$ & ARCH & $11.118(0.519)$ \\
\hline
\end{tabular}

The superscripts “+ "and “- " denote positive and negative partial sums, respectively.

SC, FF and ARCH denote LM tests for serial correlation, functional form and conditional heteroscedasticity, respectively.

$p$-values are displayed in parentheses.

The estimations and tests have been conducted using Microfit 5.0 and a program code written in STATA, produced by M. Sunder and retrieved 
from Matthew Greenwood-Nimmo’s webpage.

*** and ${ }^{* *}$ denote significance at the 1 and $5 \%$, levels, respectively. 
Table 8. Long-run price transmission elasticities

\begin{tabular}{|c|c|c|c|c|c|c|c|}
\hline \multicolumn{2}{|c|}{$\begin{array}{l}\text { (OC, US) } \\
\text { with US forcing }\end{array}$} & \multicolumn{2}{|c|}{$\begin{array}{l}\mathbf{( O C}, \mathbf{E U}) \\
\text { with EU forcing }\end{array}$} & \multicolumn{2}{|c|}{$\begin{array}{l}\text { (US, EU) } \\
\text { with EU forcing }\end{array}$} & \multicolumn{2}{|c|}{$\begin{array}{l}\text { (US, OC) } \\
\text { with OC forcing }\end{array}$} \\
\hline \multirow{2}{*}{$\beta_{O C, U S}$} & \multirow{2}{*}{$0.825 * * *$} & $\beta_{O C, E U}^{+}$ & $0.955 * * *$ & $\beta_{U S, E U}^{+}$ & $0.894^{* * *}$ & $\beta_{U S, O C}^{+}$ & $1.006 * * *$ \\
\hline & & $\beta_{O C, E U}^{-}$ & $0.900 * * *$ & $\beta_{U S, E U}^{-}$ & $0.811^{* * *}$ & $\beta_{U S, O C}^{-}$ & $0.947 * * *$ \\
\hline
\end{tabular}

$\beta$ is the estimated symmetric long-run coefficient

$\beta^{+}$and $\beta^{-}$are the estimated asymmetric long-run coefficients associated with positive and negative changes, respectively, defined by $\hat{\beta}^{+}=-\hat{\theta}^{+} / \hat{\rho}$ and $\hat{\beta}^{-}=-\hat{\theta}^{-} / \hat{\rho}$, respectively.

$* * *$ denotes significance at the $1 \%$ level. 
Figures

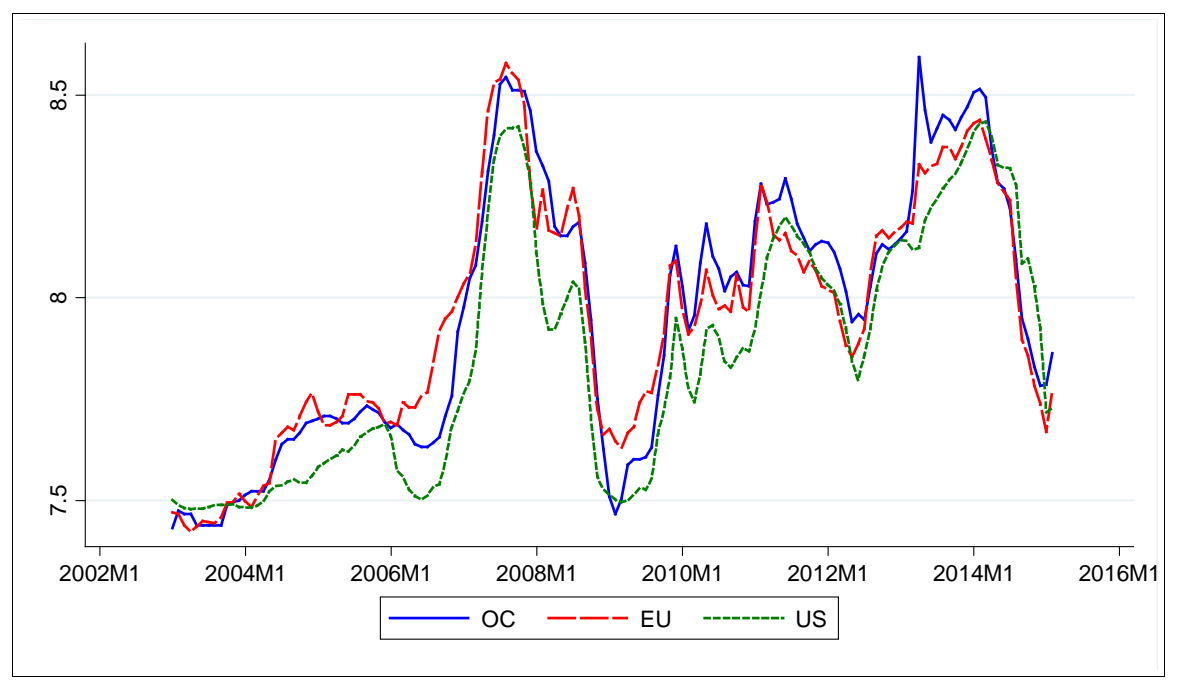

Fig. 1.The natural logarithms of the SMP prices for Oceania (OC), the European Union (EU), and the United States (US). 


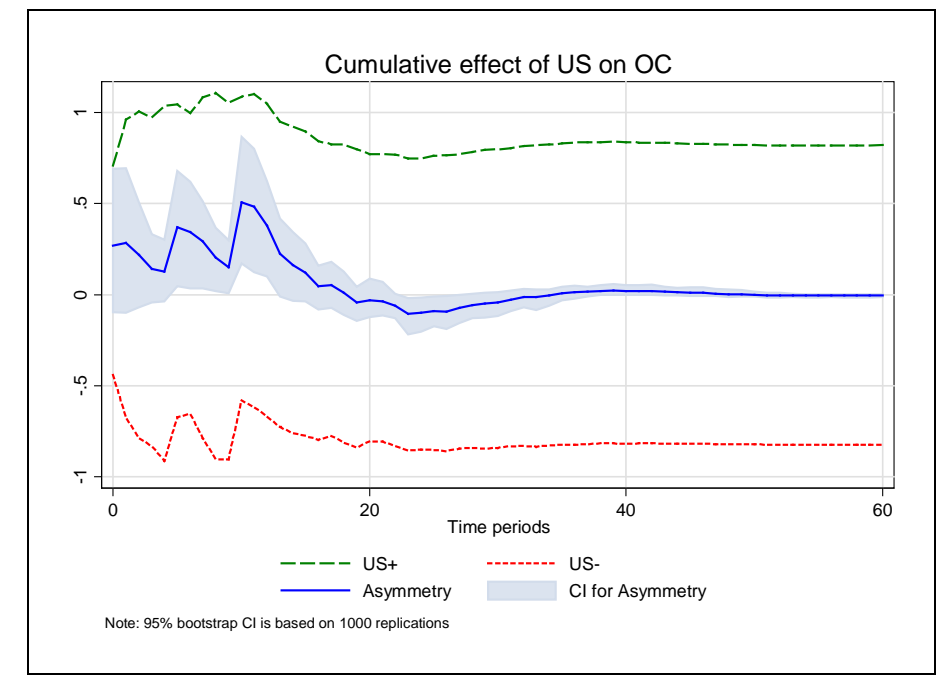

Fig. 2. Dynamic Multipliers: Pair (OC, US) with US forcing

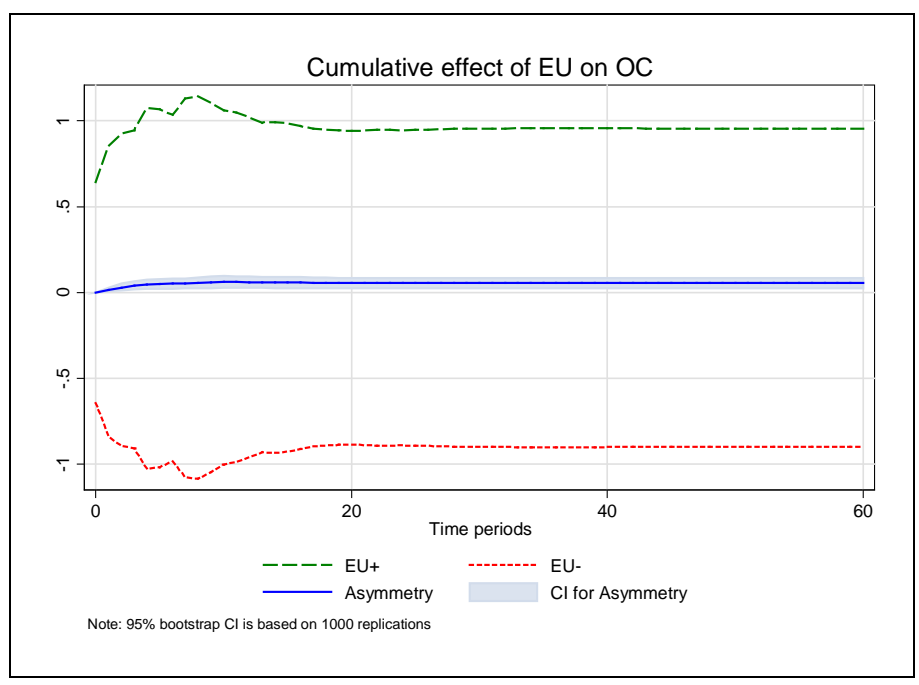

Fig. 3. Dynamic Multipliers: Pair (OC, EU) with EU forcing 


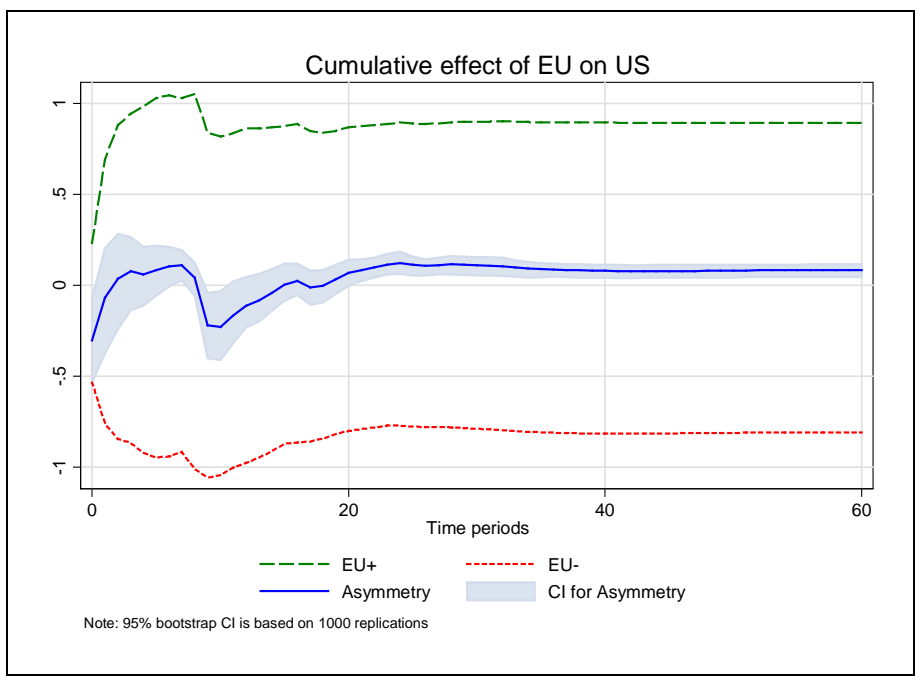

Fig.4. Dynamic Multipliers: Pair (US, EU) with EU forcing

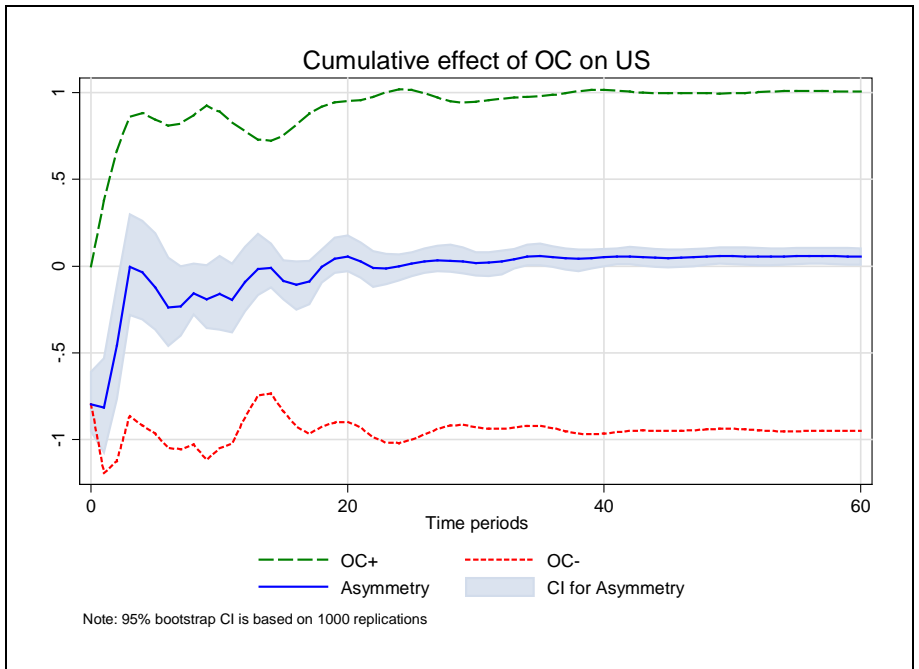

Fig.5. Dynamic Multipliers: Pair (US, OC) with OC forcing 